\title{
Correlation of Height Parameter and Pulmonary Function Test with Grade of Allergic Rhinitis and Asthma in Children
}

\author{
Sadaf Choudhary ${ }^{1}$, MD, Keya Rani Lahiri ${ }^{2}$, MD, Fehmida Najmuddin ${ }^{3}$ MD \\ ${ }^{1}$ Department of Paediatrics, Dr D Y Patil Medical College, Hospital and Research Centre Nerul, Navi Mumbai, Maharashtra \\ ${ }^{2}$ Paediatrics, Professor, Department of Paediatrics, Dr. D Y Patil Medical College, Hospital and Research Centre, Nerul, \\ Navi Mumbai, Maharashtra \\ ${ }^{3}$ Paediatrics, Assistant Professor, Department of Paediatrics, Dr. D Y Patil Medical College, Hospital and Research Centre, \\ Nerul, Navi Mumbai, Maharashtra
}

Corresponding Author: Dr. Fehmida Najmuddin; fehmidanc9@gmail.com

Received 21 July 2020;

Accepted 07 August 2020;

Published 16 August 2020

\begin{abstract}
Introduction: Allergic Rhinitis and Asthma adversely affects height in children and it could be considered as an objective tool to assess severity, compliance and lung functions in children. We studied the correlation between height and pulmonary function tests with classification of allergic rhinitis and asthma. Aims \& Objectives: 1) To study the height parameter with the grade of asthma and allergic rhinitis 2) To evaluate the pulmonary function test with the severity of asthma and allergic rhinitis 3) To correlate height and pulmonary function test with the classification of asthma and allergic rhinitis. Material and Methods: A prospective study including 30 patients in the age group of 5-12 years diagnosed with allergic rhinitis (AR) and bronchial asthma was conducted in a private tertiary care hospital in Navi Mumbai. History was entered in a pre-designed proforma and height was measured using a calibrated stadiometer along with pulmonary function tests recorded at the initial and two visits, 3 months apart. $\underline{\text { Results: }}$ Height increased significantly in patients without AR (p-value $<0.01)$, with mild intermittent (pvalue $=0.02)$ and mild persistent $A R(p$-value $<0.01)$ on subsequent visits. Patients with intermittent, mild persistent and moderate persistent asthma showed a statistically significant increase in height ( $\mathrm{p}$-value $<0.01)$ with subsequent assessments. No significant increase in height was noted in patients with moderate persistent $\mathrm{AR}(\mathrm{p}$-value $=0.14)$ and severe persistent asthma ( $\mathrm{p}$-value $=0.16)$. At baseline, the height correlated significantly with FEV1 ( $p$ value $<0.01$ ), FVC ( $p$ value $<0.01$ ), Pre and Post-PEFR ( $p$ value $<0.01$, each). This trend continued at the first follow up. At the second follow-up, height correlated significantly with all parameters of pulmonary function tests ( $p$ value $<0.01$ for FEV1, FVC, FEV1/FVC ratio and PEFR). Conclusion: Height correlation with classification of AR and Asthma along with pulmonary function test has emerged as a simple, safe, cost-effective method in assessing control and monitoring the disease.
\end{abstract}

Keywords: Allergic Rhinitis, Bronchial Asthma, Height, Pulmonary Function Test, Paediatrics

\section{Introduction}

The quality of life for children with Allergic rhinitis (AR) and Asthma is vital for the child's wellbeing and preventing school absenteeism. Asthma and Allergic rhinitis in children is a syndrome complex which affects daily activities, sleep, play, work and school activities. Growth with special reference to height is one such parameter which is immensely affected if the disease is not graded and treated appropriately in a time bound manner. The prevalence of childhood Asthma in a developing country like India, according to various studies ranges from $3.5 \%$ to $29.5 \%{ }^{[1]}$.

Spirometry is the preferred method for the diagnosis of obstruction. Airflow obstruction is defined as Forced expiratory volume (FEV1) of less than $80 \%$ predicted and a reduced FEV1/ Forced vital capacity (FVC) ratio of less than 0.8. Significant reversibility after administration of a short-acting bronchodilator is typically seen in asthma and is indicated by an increase in FEV1 of $\geq 12 \%$ from baseline. Allergic rhinitis (AR) is invariably associated with asthma in children and the prevalence of $\mathrm{AR}$ is $14.6 \%$ in the adolescent age group ${ }^{[2]}$. The classical diagnostic features include rhinorrhoea, nasal obstruction, sneezing and nasal itching.

Asthma and AR are classified as one airway one disease as proven by the strong epidemiological correlation between the two ${ }^{[3]}$. Both conditions are diseases of respiratory tract mucosa, linked by common immunological processes, and they respond to similar treatments. 
Majority of the patients have a combination of AR with Asthma, and with each episode of AR, there is an acute exacerbation of Asthma and subsequently improvement in asthma control once the rhinitis component is treated ${ }^{[4]}$. In the recent past, nutritional status, growth parameters and the course of the disease associated with Asthma has gained a lot of attention ${ }^{[5,6,7]}$. There is a paucity of studies on the correlation of height and allergic rhinitis with asthma in children. Hence, we decided to study the height parameter of children with allergic rhinitis and asthma of varying grades along with pulmonary function tests. Height and pulmonary function tests being objective parameters would ensure control and compliance of these children with its simplicity and costeffectiveness.

\section{Materials and Methods}

It was a prospective study conducted in the Department of Paediatrics of a private tertiary care hospital, from September 2016 to March 2018. The study was approved by the institutional ethical committee. Informed consent and assent was taken from parents and children who satisfied the inclusion criteria. A self-constructed semi-structural case record form was used to record the demographic details, clinical symptoms and signs. Pulmonary Function Test (PFT) parameters included FEV1, FVC, FEV1/FVC, and Peak Expiratory Flow Rate (PEFR). The study included 30 consecutive patients diagnosed with allergic rhinitis and bronchial asthma.

\section{Inclusion Criteria}

1. Age between 5 to 12 years of both sexes.

2. Patients diagnosed with Bronchial Asthma (Global Initiative for Asthma: GINA guidelines) and Allergic Rhinitis (Allergic Rhinitis and its impact on Asthma: ARIA guidelines).

3. Parents/children who have given the consent /assent.

\section{Exclusion Criteria}

1. Presence of upper and lower respiratory tract infection in the past four weeks.

2. Presence of an acute exacerbation, emergency visit, or hospitalization during the past four weeks.

3. Presence of skeletal disorders with asthma and allergic rhinitis.

4. Parents who have not given their consent.

\section{Measurement of Anthropometry}

On enrolment of subjects, demographic details and a brief history were noted in the case record form. Height was recorded by asking the patients to remove their shoes, stand against a calibrated stadiometer, their bare feet touching each other, with heel, calf, buttock, upper back, and occiput touching the wall and child looking straight ahead. A baseline height was recorded at the first visit and then on subsequent 2 nd and 3 rd visits.

\section{Pulmonary Function Testing}

Pulmonary function was assessed with a computerized spirometer (Medical International Research: MIR Spirobank G spirometer) and was performed following the protocol by American Thoracic Society ${ }^{[8]}$. FVC, FEV1 and FEV1/FVC were measured three times, the best trial being recorded. All parameters were reported as percent of the predicted for age, height, and gender ${ }^{[9]}$. PEFR was measured using a portable Peak Flow Monitor (Breath-O-Meter).
Three successive expiratory manoeuvres were performed, and the one with the highest value was recorded. The result was reported as a percentage of the predicted for age, height and gender ${ }^{[10]}$.

\section{Statistical Analysis}

Descriptive variables were expressed as mean and standard deviation for quantitative variables while for qualitative variables it was in frequency and percentages. The Chi-square test and the Student's $t$ test or the Mann-Whitney U test were used for testing differences among categorical and continuous variables along with the standard method of ANOVA. The correlation between any two parameters between the groups or within the same group was made by using Pearson's correlation coefficient. The statistical analysis was done with SPSS Version 21.0 (IBM Corp, NY) and p value less than 0.05 was taken as statistically significant.

\section{Observations and Results}

The observed age group was 8 to 10 years $(43.3 \%)$ and more than 10 years $(33.3 \%)$. Mean age of the patients was $9.1 \pm 2.02$ years with $(33.3 \%)$ females and $(66.7 \%)$ males. (Table 1). Classification of asthma revealed mild persistent $(43.3 \%)$; intermittent $(26.7 \%)$; moderate persistent (20\%) and severe persistent (10\%). (Table 2).

Classification of AR grading revealed mild intermittent and mild persistent (23.3\%) each with moderate persistent (13.3\%) (Table 3). Height was measured at baseline and two follows ups three months apart. Patients with intermittent asthma had mean height of $137.75 \pm 14.95 \mathrm{~cm}$ at baseline, which increased significantly to $139 \pm 14.40 \mathrm{~cm}$ at first follow up (p value <0.01) and $140.50 \pm 14.31$ at second follow up. Patients with mild persistent asthma had mean height of $133.46 \pm 14.45 \mathrm{~cm}$ at baseline, which increased to $136.08 \pm 13.50 \mathrm{~cm}$ and to $138 \pm 14.15$ $\mathrm{cm}$ at first and second follow up respectively. Patients with moderate persistent asthma had mean height of $136.50 \pm 8.14 \mathrm{~cm}$ at baseline, which increased to $138.83 \pm 7.52 \mathrm{~cm}$ and to $141.00 \pm 8.56$ $\mathrm{cm}$ at first and second follow up respectively. Patients with severe asthma had mean height of $124.67 \pm 9.24 \mathrm{~cm}$ at baseline, $126.67 \pm$ 11.02 at first follow up and $127.67 \pm 11.85$ at second follow up. Significant increment in the height of intermittent, mild persistent and moderate persistent asthma was observed but not in the severe persistent type (Graph 1).

There was a significant increment in height of patients with mild intermittent and mild persistent allergic rhinitis. There was an increase in mean height in moderate persistent allergic rhinitis which was not statistically significant ( $p$ value-0.14) (Graph 2). The baseline and first follow-up height correlated significantly with FEV1 (forced expiratory volume in one minute), FVC (forced vital capacity), Pre and Post PEFR (Peak Expiratory Flow rate) but not the FEV1/FVC ratio.

However, the second follow up revealed significant correlation of height with all the four parameters of pulmonary function test (FEV1, FVC, FEV1/FVC, PEFR). (Table 4).

Table 1: Distribution of Patients According to their Gender

\begin{tabular}{|c|c|c|}
\hline Gender & N & $\%$ \\
\hline Female & 10 & $33.3 \%$ \\
\hline Male & 20 & $66.7 \%$ \\
\hline Total & 30 & $100.0 \%$ \\
\hline
\end{tabular}


Table 2: Distribution of Patients According to their Severity of Bronchial Asthma

\begin{tabular}{|c|c|c|}
\hline Asthma Grade & $\mathbf{N}$ & $\%$ \\
\hline Intermittent Asthma & 8 & $26.7 \%$ \\
\hline Mild persistent & 13 & $43.3 \%$ \\
\hline Moderate persistent & 6 & $20.0 \%$ \\
\hline Severe persistent & 3 & $10.0 \%$ \\
\hline Total & 30 & $100.0 \%$ \\
\hline
\end{tabular}

Table 3: Distribution of Patients According to their Severity of Allergic Rhinitis

\begin{tabular}{|c|c|c|}
\hline Allergic Rhinitis Grade & N & $\%$ \\
\hline Absent & 12 & $40.0 \%$ \\
\hline Mild intermittent & 7 & $23.3 \%$ \\
\hline Mild persistent & 7 & $23.3 \%$ \\
\hline Moderate persistent & 4 & $13.3 \%$ \\
\hline Total & 30 & $100.0 \%$ \\
\hline
\end{tabular}

Table 4: Correlation of Height with Various Parameters of Pulmonary Function Test at Different Follow-up visits

\begin{tabular}{|c|c|c|}
\hline \multicolumn{3}{|c|}{ Pearson co-relation } \\
\hline Height (Baseline) & r value & $\mathrm{p}$-value \\
\hline FEV1 & 0.89 & $<0.01$ \\
\hline FVC & 0.86 & $<0.01$ \\
\hline FEV1/ FVC & 0.09 & 0.65 \\
\hline Pre PEFR & 0.74 & $<0.01$ \\
\hline Post PEFR & 0.86 & $<0.01$ \\
\hline \multicolumn{3}{|l|}{ Height (1st follow up) } \\
\hline FEV1 & 0.86 & $<0.01$ \\
\hline FVC & 0.82 & $<0.01$ \\
\hline FEV1/ FVC & -0.14 & 0.45 \\
\hline Pre PEFR & 0.65 & $<0.01$ \\
\hline Post PEFR & 0.76 & $<0.01$ \\
\hline \multicolumn{3}{|l|}{ Height (2nd follow up) } \\
\hline FEV1 & 0.77 & $<0.01$ \\
\hline FVC & 0.71 & $<0.01$ \\
\hline FEV1/ FVC & 0.17 & $<0.01$ \\
\hline Pre PEFR & 0.68 & $<0.01$ \\
\hline Post PEFR & 0.66 & $<0.01$ \\
\hline
\end{tabular}

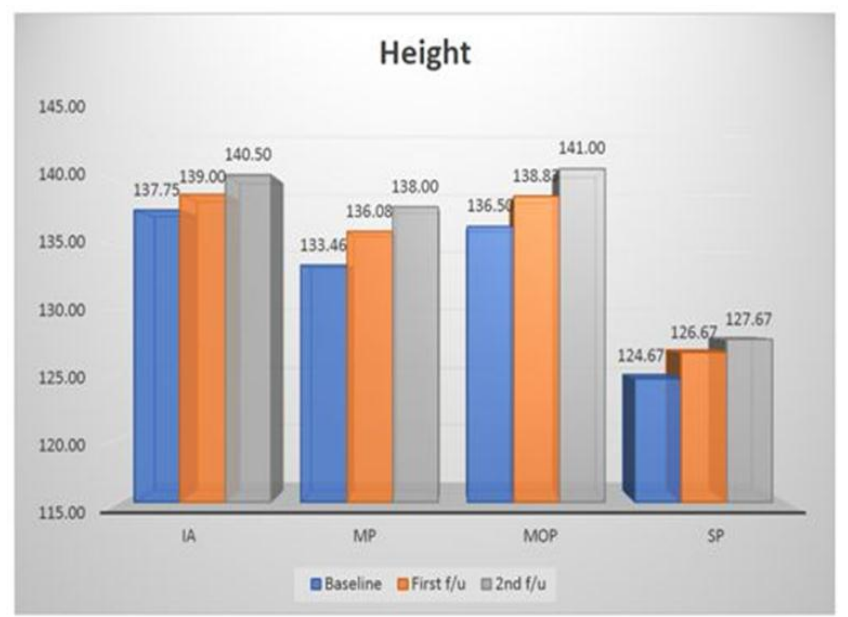

GRAPH 1: Comparing Mean Height of Patients with Different Asthma Severity at Different Follow-up visits

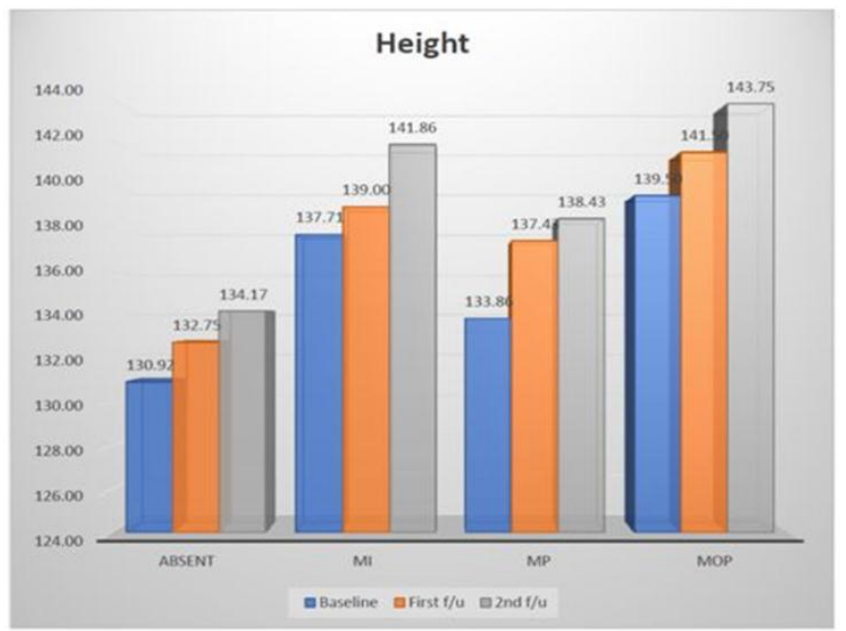

Graph 2: Comparing Mean Height of Patients with Different Severities of Allergic Rhinitis at Different Follow-up visits

\section{Discussion}

Majority of the patients were in the age group of 8 to 10 years, followed by 10 to 12 years and 5 to 7 years. Male preponderance was seen in our study as reported by Naik et al who found higher prevalence of asthma in males (3.3\%) compared to females (2.9\%) ${ }^{[11]}$. Anuradha et al, showed male dominance in $(71.66 \%)^{[12]}$. Horwood et al observed that the prevalence of asthma is nearly twice in boys than girls before the age of $14^{[13]}$.

Allergic rhinitis has emerged as a major risk factor associated with development of Bronchial Asthma in children and their association has been widely studied ${ }^{[14]}$.

A significant increase in mean height was observed in children with mild intermittent, mild persistent $\mathrm{AR}$ and those without the AR component. However; the subjects with moderate AR severity showed insignificant change in height parameter.

The severe persistent asthmatics constituted only $10 \%$ of the patients who did not show any increase in the height parameter. Higher doses of inhaled corticosteroids and poor compliance may account for diminished increase in height velocity. The height in children is positively influenced by the synthesis of somatotropin in response to physical training and subsequently cause height affection in severe asthmatics as they are unable to perform various sports activities ${ }^{[15]}$.

There was a significant correlation between height and Pulmonary function tests (FEV1, FVC, PEFR) on the first followup ; however on second visit, all the parameters of PFT ( FEV1, 
FVC, FEV1/FVC AND PEFR) showed noteworthy statistical correlation.

The positive correlation of height with PFT probably makes the height of asthmatic and allergic patients a good prognostic indicator for assessing compliance and disease control. The anthropometric measurements of weight, height, hip circumference and body surface area have been found to be positively correlated to the pulmonary function tests ${ }^{[16,17]}$. Nystad et al. prepared a linear regression model which showed that standing height was a satisfactory predictor of lung function and the explained fraction of variance (R2) was $59 \%$ for FEV1 ${ }^{[18]}$. Hence our study revealed that height parameter probably aids in identifying the compliance to treatment and serves as a good prognostic indicator. There was an inverse correlation between significant increase in height and severity of AR and asthma in our subjects.

As observed in one of the study, an increase in asthma severity was associated with reduction in height parameter and the patients with lower grade of asthma classification did not show any significant change as compared to their healthy peers ${ }^{[19]}$.

\section{Conclusion}

Children with allergic rhinitis and bronchial asthma exhibit height as a distinctive parameter for growth, compliance, daily activities, grading and prognosis. Height parameter may be proposed as an objective, simple, safe, and cost-effective tool for assessment of growth and lung functions amongst AR and asthmatic children.

\section{Source of support: NIL}

\section{Conflict of interest: NIL}

\section{References}

[1] Sharma S, Gupta RC, Dixit R, Sharma S, Gupta N. Prevalence of asthma in school children with allergic condition in rural areas of Ajmer, India. Chest. 2008 134: p54001.

[2] Ai_t-Khaled N, Pearce N, Anderson HR, Ellwood P, Montefort S, Shah J; ISAAC Phase Three Study Group. Global map of the prevalence of symptoms of rhinoconjunctivitis in children: the International Study of Asthma and Allergies in Childhood (ISAAC) phase three. Allergy 2009;64:123-48.

[3] Leynaert B, Neukirch F, Demoly P, Bousquet J. Epidemiologic evidence for asthma and rhinitis comorbidity. J Allergy Clin Immunol 2000;106(5 Suppl):S201-5.

[4] Erbas B, Akram M, Dharmage SC, Tham R, Dennekamp $\mathrm{M}$, Newbigin E, et al. The role of seasonal grass pollen on childhood asthma emergency department presentations. Clin Exp Allergy 2012;42:799-805.

[5] Giannini C., Mohn A., Chiarelli F. Growth abnormalities in children with type 1 diabetes, juvenile chronic arthritis, and asthma. International Journal of Endocrinology. 2014;2014 doi:
10.1155/2014/265954.265954 [PMC free article] [PubMed] [CrossRef].

[6] Wiesenthal E. N., Fagnano M., Cook S., Halterman J. S. Asthma and overweight/obese: double trouble for urban children. Journal of Asthma. 2016;53(5):485-491. doi: 10.3109/02770903.2015.1108435.[PMC free article] [PubMed] [CrossRef].

[7] Eliseeva T. I., Geppe N. A., Ignatov S. K., et al. Relative body mass index as a new tool for nutritional status assessment in children and adolescents with bronchial asthma. Sovremennye tehnologii $\mathrm{v}$ medicine. 2017;9(1):135-148. doi: 10.17691/stm2017.9.1.18. [CrossRef].

[8] Miller MR, Crapo R, Hankinson J, Brusasco V, Burgos F, Casaburi R, et al. General considerations for lung function testing. Eur Respir J 2005;26:153_61.

[9] Pereira CA, Barreto SP, Simões JG, Pereira FW, Gerstler JG, Nakatani J. Valores de refere_ncia para espirometria em uma amostra da populac _ão brasileira adulta. J Pneumol. 1992;18:10-22.

[10] Gregg I, Nunn AJ. Peak expiratory flow in normal subjects. Br Med J. 1973;3:282-4.

[11] Naik P, Ravikumar P. Study of prevalence of bronchial asthma in school children of 6-12 years of age in rural schools of Tumakuru district. Indian Journal of Allergy, Asthma and Immunology. 2017 Jul 1;31(2):56-.

[12] Anuradha A, Kalpana VL, Narsingarao S. Epidemiological study on bronchial asthma. Indian $\mathrm{J}$ Allergy Asthma Immunology 2011; 25:85-9.

[13] Horwood LJ, Fergusson DM, Shannon FT. Social and familial factors in the development of early childhood asthma. Pediatrics 1985;75:859-68.

[14] Asher I. ISAAC International study of asthma and allergies in childhood. Pediatric Pulmonol 2007; 42:100.

[15] E. Richmond and A.D. Rogol "Endocrine responses to exercise in the developing child and adolescent" in Sports Endocrinology, F. Lanfranco and C. J. Strasburger, Eds., vol. 47, pp. 58-67, 2016.

[16] Surve RR, Dase RK. The association between pulmonary function test and anthropometric measurements using bioelectric impidence analysis in adolescents. International Journal of Community Medicine and Public Health. 2018 Aug 24;5(9):3936-41.

[17] Pawar S, Taksande AB. Prediction of pulmonary norms in healthy school boys 5-15 years - A review article. J Mahatma Gandhi Institute Med Sci. 2011; 16(1).

[18] Nystad W, Samuelsen SO, Nafstad P, Edvardsen E, Stensrud T, Jaakkola JJ. Feasibility of measuring lung function in preschool children. Thorax. 2002 Dec 1;57(12):1021-7.

[19] Eliseeva TI, Geppe NA, Ignatov SK, Soodaeva SK, Tush EV, Khaletskaya OV, Potemina TE, Malakhov AB, Kubysheva NI, Solovyov VD. Relative body mass index as a new tool for nutritional status assessment in children and adolescents with bronchial asthma. Современные технологии в медицине. 2017; 9(1 (eng)). 